\title{
INVESTIGACIÓN SOBRE PUBLICIDAD DIGITAL EN REVISTAS CIENTÍFICAS ESPAÑOLAS
}

Esther Martínez-Pastor y Javier García-López

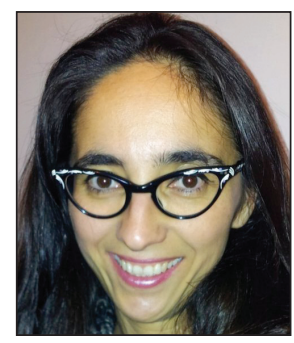

Esther Martínez-Pastor es profesor contratado doctor de la Facultad de Ciencias de la Comunicación de la Universidad Rey Juan Carlos. Es doctora en ciencias de la comunicación por la Universidad Complutense de Madrid y licenciada en derecho por la Universidad Nacional de Educación a Distancia. Sus líneas de investigación se centran en el derecho de la publicidad, en la publicidad institucional de las adminitraciones públicas y en la inmigración.

http://orcid.org/0000-0002-2861-750X

Universidad Rey Juan Carlos 28943 Fuenlabrada (Madrid), España esther.martinez.pastor@urjc.es

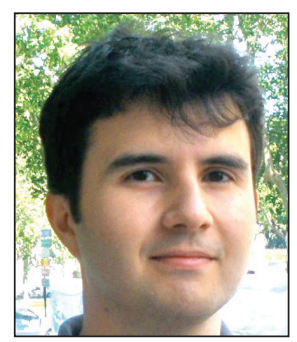

Javier García-López es profesor contratado doctor en la Universidad a Distancia de Madrid, donde imparte las asignaturas publicidad, opinión pública e historia de la comunicación social. Anteriormente ha sido profesor en la Universidad San Jorge de Zaragoza, en el área de publicidad. Obtuvo el doctorado en comunicación y la licenciatura en publicidad. Es autor de diversos artículos científicos, capítulos de libro y monografías. Es especialista en epistemología y gnoseología, así como en comunicación institucional y de la empresa.

http://orcid.org/0000-0002-7306-4289

Universidad a Distancia de Madrid Carr. de La Coruña, KM.38,500. Vía de servicio, n. 15 28400 Collado Villalba (Madrid), España javier.garcia@udima.es

\section{Resumen}

Revisión del estado de la cuestión sobre la publicidad digital en las revistas de mayor impacto en España desde 2002. El objetivo es conocer qué temas son los más tratados y cuáles son las contribuciones teóricas y prácticas aportadas por los autores. Se toma como referencia el trabajo de Louisa Ha (2008) que realizó un estado del arte sobre los estudios de publicidad digital publicados en las principales revistas. Se parte de las revistas incluidas en In-Recs, área de comunicación. Los trabajos localizados se han categorizado en función de su análisis científico en: actitud hacia la publicidad digital, internet como medio publicitario, interactividad en la publicidad, proceso y ejecución de publicidad digital, medición de la audiencia, sinergias de la publicidad online y offline y aspectos educativos sobre la publicidad digital.

\section{Palabras clave}

Publicaciones, Investigación, Publicidad digital, Revistas científicas.

\section{Title: Review of Spanish scientific journals research on digital advertising}

\begin{abstract}
This article is a review of the state of the art on digital advertising in major journals in Spain since 2002. The objective is to determine what issues are the most discussed and the theoretical and practical contributions made by the authors. It draws on the work of Louisa $\mathrm{Ha}$ (2008), a state-of-the-art on digital advertising studies published in major journals. Our starting point is all journals included in the In-Recs Spanish communication area journals ranking. The studies are categorized according to their scientific analysis into seven categories: attitude towards online advertising, internet as an ad medium; interactivity in online advertising, online ad processing and execution, audience measurement, online/offline advertising synergies and online advertising education.
\end{abstract}

\section{Keywords}

Publications, Research, Online advertising, Scientific journals, Communication journals.

Martínez-Pastor, Esther; García-López, Javier (2013). “Investigación sobre publicidad digital en revistas científicas españolas". El profesional de la información, 2013, marzo-abril, v. 22, n. 2, pp. 173-180.

http://dx.doi.org/10.3145/epi.2013.mar.12 


\section{Publicaciones científicas sobre temas de publicidad digital}

El interés en conocer el estado del arte de los estudios científicos en relación a la publicidad digital se debe al vertiginoso desarrollo e inversión de los anunciantes en medios digitales. Un estudio de PricewaterhouseCoopers $(P w C)$ y de la Interactive Advertising Bureau Spain (IAB) indica que durante 2011 la inversión en medios digitales fue de 899,24 millones de euros, ocupando la tercera posición, con un 16,3\% del total; precedida, en primer lugar, por la televisión, con un $40,6 \%$, y seguida de los diarios, con un $17,6 \%$. De este total, en internet se realizó un desembolso del 883,1 millones de euros $(98,2 \%)$ y en los móviles 16,1 millones de euros $(1,8 \%)$. De modo que el crecimiento publicitario en el soporte digital ha aumentado un 12,6\% del año 2010 al 2011 frente a los demás medios convencionales, que han visto disminuir su inversión. Aunque hay que señalar que de esta cuantía no todo revierte en un beneficio directo sobre los distintos actores de la industria publicitaria, ya que la publicidad en internet está determinada por la publicidad en buscadores, cuyos beneficios van a parar a empresas como Google. Destacamos así el auge de este medio como soporte publicitario. Desde el punto de vista estricto de la teoría de la publicidad, se considera internet como un medio publicitario (Berthon et al., 1996: 43-54). Incluso Infoadex (2012), desde la perspectiva profesional, sitúa internet como un medio convencional en el que los anunciantes pueden invertir con su publicidad. Sin embargo, desde una óptica académica general, hay que tener en cuenta que internet es un canal en el que se incluyen los demás medios de comunicación. No obstante, los datos muestran que los anunciantes han apostado claramente por la inversión en medios digitales frente a los tradicionales y explica nuestro interés en conocer si este tema se ha tratado en la investigación académica.

Se entiende por publicidad digital aquella cuyos "mensajes son ubicados de forma deliberada en sitios web de 'terceros', incluyendo los motores de búsqueda y directorios disponibles a través de internet" (Ha, 2008, pág. 31). Se excluyen de esta definición los webs tienda tipo Amazon y los emails. De igual modo, la publicidad digital es un concepto amplio que no necesariamente implica la interactividad -la publicidad interactiva, además de ser digital, requiere de una interacción directa por parte del usuario (Blattberg; Deighton, 1991)-.

Se han realizado diversos estudios bibliográficos sobre temas publicitarios, como el de Roca y Mensa (2009), que trabaja sobre las metodologías utilizadas en la investigación de la creatividad publicitaria; el estudio de Del-Río-Pérez (2006), quien lleva a cabo una revisión sobre la literatura científica en el área de publicidad, o el estado del arte de Martínez-Pestaña (2004) sobre la producción de tesis doctorales en temas publicitarios (1971-2001).

Nuestra investigación se centra en los estudios sobre publicidad digital que incluyen la interactividad.

\section{Método}

El método utilizado es hipotético-deductivo. De un lado, se parte de la recopilación de datos, se sigue con la ordenación de los mismos y se finaliza con la realización de conclusiones aplicables a todo el conjunto. De otro lado, se realizan deducciones lógicas de los datos. Nuestro principal objetivo es conocer el tipo de investigaciones que se están llevando a cabo sobre publicidad digital. El objetivo secundario es identificar las temáticas preferidas por los investigadores y detectar las carencias de trabajos en determinadas áreas. El tercer objetivo implica correlacionar si las investigaciones realizadas corresponden a la realidad empresarial y dan solución a los problemas y necesidades que requiere el mercado.

Partimos de la muestra de 24 revistas incluidas en la sección Comunicación del In-Recs (Índice de impacto de las revistas españolas de ciencias sociales, del Grupo EC3 de la Universidad de Granada), edición de 2010 (tabla 1), que recoge las revistas españolas de ciencias sociales de más calidad. Se ha optado 


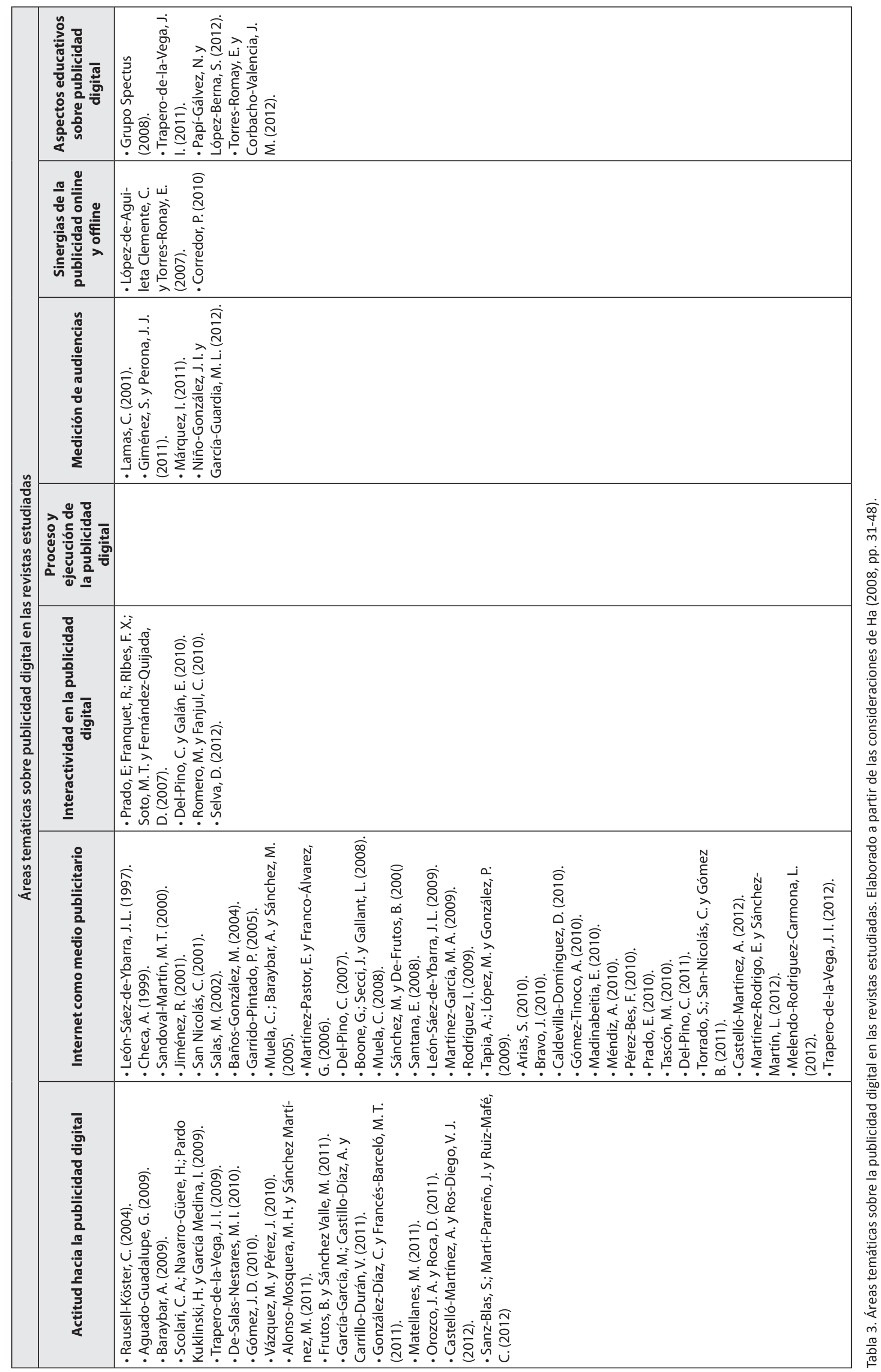


por la elección de todas las revistas científicas de comunicación y no delimitar la muestra a las revistas exclusivamente de publicidad ya que In-Recs sólo recoge dos, Questiones Publicitarias y Pensar la publicidad.

La búsqueda en las revistas se llevó a cabo con los descriptores "publicidad digital", "publicidad" o "publicitario" y "digital". En las revistas que carecían de buscador la búsqueda se hizo de forma manual. Se tomó como punto de partida el trabajo de $\mathrm{Ha}$ (2008) y se categorizaron los trabajos en los siguientes 7 temas: actitud hacia la publicidad digital; internet como medio publicitario; interactividad en la publicidad; proceso y ejecución de la publicidad digital; medición de audiencias; sinergias de la publicidad online y offline; y aspectos educativos sobre la publicidad digital.

De las 24 revistas, 9 no tienen artículos relacionados con publicidad digital: Comunicar, Estudios sobre el mensaje periodístico, Ámbitos, Anàlisi, CIC, I/C, Mediaciones sociales, Historia y comunicación social, y Coneixement i societat. En ellas hemos detectado estudios afines al objeto de nuestra investigación sobre internet pero no sobre publicidad digital.

De las 15 revistas restantes (Revista latina; Comunicación y sociedad; Zer; Telos; Doxa; Área abierta; Sphera pública; Trípodos; Revista de la Seeci; Comunicación; Questiones publicitarias; Icono 14; Comunicación y hombre; Pensar la Publicidad, y Vivat Academia) se ha seleccionado una muestra de 64 artículos sobre publicidad digital del período 2002 al 2012 (tabla 2).

\section{Resultados}

Atendiendo a los 64 artículos objeto de la muestra, que versan sobre diversas materias que se han publicado en las revistas analizadas, existe una carencia relativa de artículos sobre el objeto de estudio que nos ocupa. La publicidad digital es la tercera fórmula de mayor inversión, como lo muestra el estudio Infoadex (2011), si bien no está lo suficientemente atendida por la literatura científica sobre publicidad (gráfico 1).

Se han localizado 16 artículos (25\%) que versan sobre la actitud que presentan los diferentes actores publicitarios frente a la publicidad online; $34(53,1 \%)$ que estudian internet como un medio publicitario; $4(6,3 \%)$ que trabajan el concepto de la interactividad en la publicidad en red; 4 (6,3\%) sobre medición de audiencias en este contexto; 2 (3,1\%) que estudian las sinergias existentes entre la publicidad online y offline; y $4(6,3 \%)$ que analizan aspectos educativos sobre publicidad en internet. No se han encontrado artículos sobre el proceso y ejecución de la publicidad digital, que sí aparecen en el trabajo de Ha (2008, pág. 31-48).

\section{Actitud hacia la publicidad digital}

El primer trabajo encontrado sobre actitud hacia la publicidad digital es el de Rausell-Köster (2004), quien marca la actitud de anunciantes y usuarios de internet ante la publicidad online en un primer momento. Los emisores publicitarios españoles están poco acostumbrados al emergente medio y no hacen uso de las potencialidades comunicativas del medio, en contraposición a lo que ocurre en países más avanzados en estas vicisitudes (Ha, 2008, pág. 34). Existe una especie de "brecha digital publicitaria", como indica Trapero-de-la-Vega (2009), que demuestra el escaso uso del medio internet por parte de los actores publicitarios en España. Otro estudio argumenta que el usuario se convierte en creador de contenidos, lo que requiere una especialización del mensaje corporativo, con el objetivo de generar fidelización (García-García et al., 2011). Ello es corroborado por Alonso-Mosquera y Sánchez-Martínez (2011) que consideran que las marcas de alimentación, cuyo público objetivo es el segmento infantil, utilizan cada vez más sus páginas web para interactuar con los receptores y potenciales consumidores, provocando posibles efectos de alineación positiva hacia el producto.

Las actitudes de emisores y receptores muestran la necesidad de una regulación publicitaria, ya que el medio no asegura la protección de usuarios en muchos casos. Aguado (2009) propone que la escasa regulación del medio provoca situaciones de desigualdad. Los mensajes de algunas marcas esquivan la legalidad de los medios convencionales. De igual modo, el artículo de Gómez-Castallo (2010) apuesta en sus conclusiones por la autorregulación publicitaria por parte de las empresas. La red es un medio publicitario en el que se debe apostar por la responsabilidad empresarial y comunicativa, como afirman Baraybar (2009) y Orozco y Roca (2011).

Por otro lado, las redes sociales, el marketing móvil y los videojuegos en red configuran nuevas posibilidades de comunicación. Las redes sociales "conectan" con consumidores y clientes, tomado como referencia cómo se relacionan los receptores en estas plataformas (De-Salas, 2010; Castelló; Ros, 2012), y tienen una capacidad única de segmentación (Matellanes, 2011). Por su parte, el marketing móvil forja un proceso de comunicación directa e interactiva en auge (Scolari, 2009). Finalmente, el advergaming es un recurso publicitario que las marcas utilizan cada vez más para revalorizar su notoriedad y para conectar con una audiencia específica (González-Díaz; Francés, 2011).

\section{Internet como medio publicitario}

Existen numerosos artículos centrados en la descripción general de la Red que abarcan desde la definición de la publicidad digital hasta el análisis de su estructura y de sus tendencias.

Según Del-Pino (2007), en los medios convencionales existe una saturación que facilita la efectividad de los mensajes a través de la red, con una apariencia nueva, al funcionar de un modo viral. Sin embargo, como argumentan Torrado et al. (2011), en internet se engaña al receptor con el objetivo de vender un producto o conseguir la adhesión a una marca por medio de "mentiras desbocadas".

En los últimos años destacan las investigaciones sobre publicidad en soportes móviles y a través de las redes sociales. Hay estudios que aseguran que los teléfonos móviles y las redes sociales conforman plataformas de comunicación interactiva con los usuarios. Así, los efectos publicitarios tienen mayor garantía que con los medios convencionales (Martínez-García, 2009; Caldevilla, 2010). Por un lado, las 


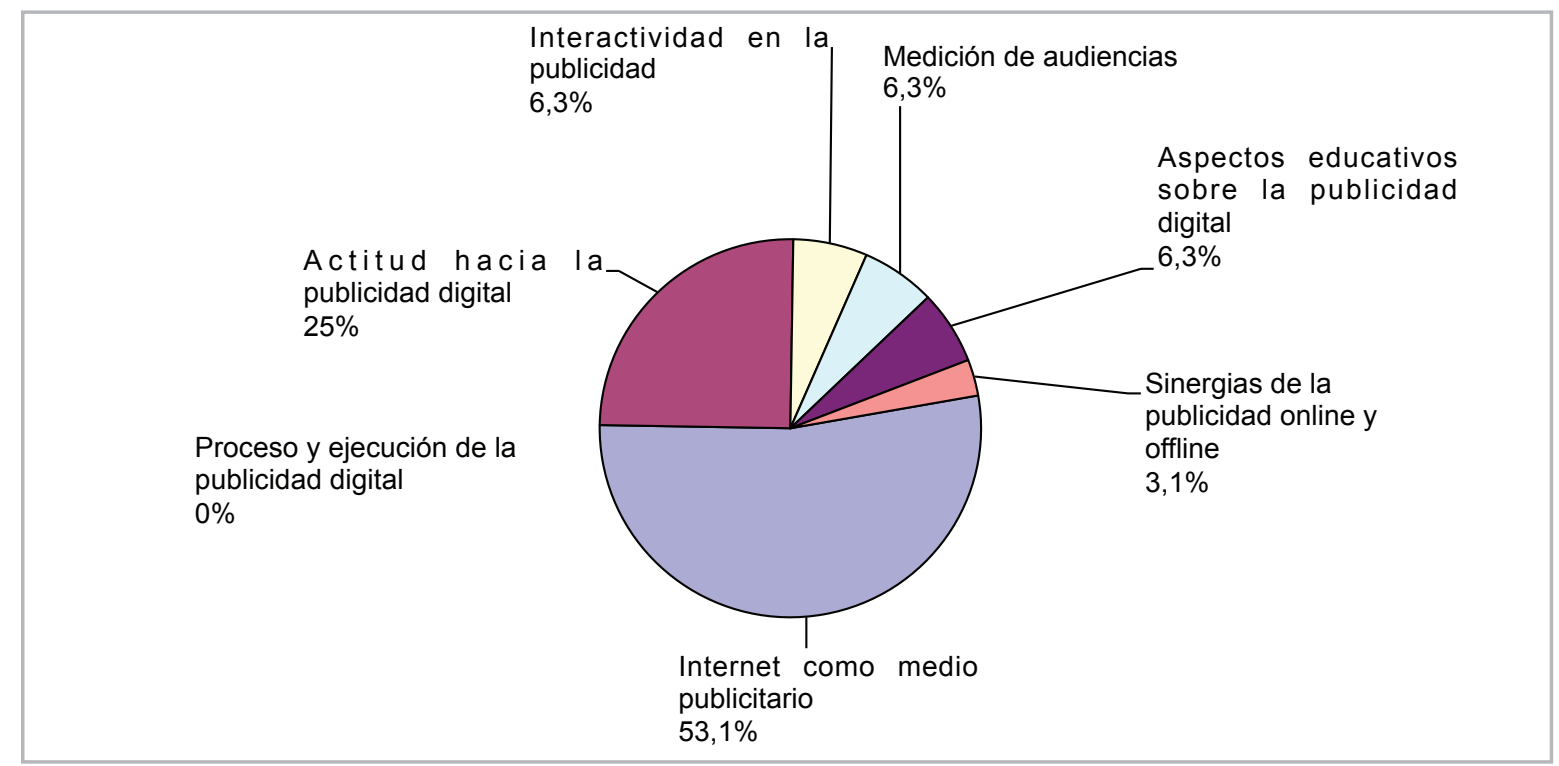

Gráfico 1. Distribución temática de los 64 artículos seleccionados

redes sociales son comunidades cerradas de consumidores potenciales con perfiles y deseos comunes (Del-Pino, 2011) y generan valor de marca (Martínez-Rodrigo; SánchezMartín, 2012); sin embargo, los actores publicitarios deben asumir restricciones legales (Pérez-Bes, 2010). De otro lado, la publicidad a través de las plataformas móviles es otra estrategia original; allí, el consumidor está predispuesto a aceptar el "chantaje" de recibir publicidad, ya que a cambio puede obtener beneficios de las empresas anunciantes (Melendo, 2012). Éstas ofrecen incentivos a los usuarios "dóciles" a cambio de información valiosa para comunicarse con ellos (Gómez-Tinoco, 2010).

Por último, la novedad investigadora la fijan los videojuegos online. Son trabajos descriptivos como los de Tapia, et al. (2009), quienes realizan una revisión de los conceptos advertainment, advergame y publicidad in-game y analizan la situación actual; y Méndiz (2010), quien habla del advergaming como una forma interactiva de comunicación comercial que puede explotarse online.

\section{Interactividad en la publicidad digital}

Aunque no queda demostrado de manera objetiva, se augura la disolución del esquema publicitario tradicional, atendiendo a los cambios mediáticos de la sociedad actual (Del-Pino; Galán, 2010). No obstante, la interactividad potencia "una experiencia sensorial" en los usuarios (Romero; Fanjul, 2010).

La interactividad de la publicidad digital abarca diferentes estadios como el de la televisión interactiva (Prado, et al., 2007), las experiencias musicales interactivas (Márquez, 2011), por medio del cloud computing y el concepto de streaming, e incluso el videoclip a través de internet (Selva, 2012).

\section{Medición de audiencias}

Los artículos sobre medición de audiencias de publicidad digital son escasos; únicamente existen tres trabajos.

El primero muestra el panorama actual de la medición de audiencias en el medio internet y su relación con la publicidad. Resalta la indeterminación en este tipo de mediciones, fundamentadas en una ingente cantidad de enfoques diversos (Lamas, 2010). El segundo artículo trata sobre el impacto de los medios sociales en la relación entre usuarios y marcas (Giménez-Cisneros; Perona, 2011). El tercero es un análisis de recepción de la publicidad interactiva en el teléfono móvil: la vía primordial es a través de sms, sistema que mejor acepta y comprende el receptor. Cuanto más cómodo se siente el usuario, mayor grado de aceptación existe con la publicidad (Niño; García-Guardia, 2012).

\section{Sinergias de la publicidad online y offline}

López-de-Aguileta y Torres (2007) reflexionan sobre la aparición de nuevos medios para la difusión de los mensajes publicitarios convencionales. Para estos autores, la utilización de medios y soportes alternativos es una nueva vía publicitaria para sorprender al receptor.

Por su parte, Corredor (2010) destaca la importancia de utilizar las buenas prácticas creativas de los medios convencionales e integrarlas en el medio digital, atendiendo a sus peculiaridades interactivas.

\section{Aspectos educativos sobre publicidad digital}

Existe una tendencia en auge en los últimos años hacia el estudio de la innovación y la investigación sobre aspectos pedagógicos. Como explica el Grupo Spectus (2008), la Red ofrece la posibilidad de complementar los procesos de aprendizaje tradicionales.

Con la reforma universitaria española, los nuevos grados incorporan competencias necesarias en el ámbito digital. Así lo demuestra el artículo de Papí y López-Berna (2012). Además, los nuevos formatos, como las redes sociales, deben ser incluidos en las competencias que los profesionales de la publicidad deben adquirir. Así, Torres y Corbacho (2012) reflexionan sobre la integración de las redes sociales en la formación universitaria en publicidad. En España, las redes sociales se asocian con actividades lúdicas y no de enseñan- 
za y el artículo propone una conjunción de ambas para un mejor aprovechamiento.

Otro aspecto es el de la publicidad de las propias instituciones educativas. En esta línea, Trapero-de-la-Vega (2011) analiza la publicidad "educativa" en las facultades de comunicación españolas y percibe un cierto retraso en la utilización de las aplicaciones de internet.

\section{Proceso y ejecución de la publicidad digital}

No hemos encontrado investigaciones que tratan dicha temática. Existen algunos trabajos relacionados con los procesos y las formas de ejecución de la publicidad online, como los de Checa (1999), Baños (2004) y Trapero-de-la-Vega (2012), quienes describen ciertos procesos creativos de la publicidad en internet. Sin embargo, no se trata de investigaciones sobre la ejecución publicitaria en red, sino de descripciones generales.

\section{Conclusiones}

El panorama general de esta investigación deja patente que la publicidad digital es un tema de interés para la comunidad científica ya que desde el año 2002 hasta el 2012 hay 64 contribuciones científicas sobre el tema. Quizá lo más llamativo es que la mayoría de los estudios se centren en la actitud de la publicidad digital (25\%) y en internet como medio publicitario $(53,13 \%)$ de la totalidad de la muestra. Se entiende que analizar la naturaleza del medio, la regulación o la autorregulación, los formatos publicitarios y las tendencias son objetos de estudio para los investigadores que disponen de un marco teórico que pueden aplicar a nuevos fenómenos. Mientras que estudiar el proceso y ejecución de la publicidad digital, la medición de audiencias y las sinergias de la publicidad online y offline requiere de herramientas profesionales ad hoc y de ser conocedor de unas dinámicas de trabajo que a menos que se trabaje en una agencia o en un medio especializado es difícil adquirir. Sin embargo, éstas son las áreas de mayor interés por las empresas digitales porque son las que muestran los resultados y el éxito de sus inversiones. Se requiere aunar fuerzas entre la empresa y los científicos para poder solventar los problemas a los que cotidianamente se enfrentan los usuarios y empresarios en el mercado, y ofrecer soluciones que posibiliten avances en el área de la publicidad digital. Los resultados de la investigación demuestran la necesidad de llevar a cabo análisis específicos sobre la realización publicitaria en internet, más allá de su descripción.

\section{Bibliografía}

Aguado, Guadalupe (2009). "Estrategias interactivas en la publicidad de productos de especial regulación: entre la internacionalización y la corregulación". Área abierta, n. 22, pp. 1-10.

http://revistas.ucm.es/index.php/ARAB/article/view/ ARAB0909130001A

Alonso-Mosquera, María-Henar; Sánchez-Martínez, María (2011). "Estrategias de comunicación interactivas en los sitios web de marcas de alimentación dirigidas al público infantil". Pensar la publicidad, v. 5, n. 2, pp. 119-138. http://revistas.ucm.es/index.php/PEPU/article/view/37866
Baños González, Miguel (2004). “Internet ¿Una puerta abierta a la publicidad?". Icono 14, v. 1, n. 3, pp. 1-18. http://www.icono14.net/ojs/index.php/icono14/article/ viewFile/444/319

Baraybar, Antonio (2009). "Conectando valores. Las nuevas estrategias de la comunicación online en el tercer sector". Icono 14, v. 7, n. 2, pp. 37-55.

http://www.icono14.net/revista/num13/3_icono13_antoniobaraybar.pdf

Berthon, Pierre; Leyland, F. Pitt; Watson, Richard T. (1996). "The World Wide Web as an advertising medium: toward an understanding of conversion efficiency". Journal of advertising research, Jan.-Feb., v. 36, n. 1, pp. 43-54.

Bezjian-Avery, Alexa; Calder, Bobby; lacobucci, Dawn (1998). "New media interactive advertising vs. traditional advertising". Journal of advertising research, v. 38, n. 4, pp. 23-32.

Blattberg, Robert; Deighton, John (1991). "Interactive marketing: exploiting the age of addressability". Sloan management review, v. 33, n. 1, pp. 5-14.

http://sloanreview.mit.edu/article/interactive-marketingexploiting-the-age-of-addressability

Caldevilla, David (2010). "Nuevas lecturas del concepto publicidad a partir de las TIC". Questiones publicitarias, v. 1, n. 15, pp. 35-51.

http://www.maecei.es/pdf/n15/articulos/3_Nuevas lecturas_del_concepto_de_publicidad_a\%20partir_de_las_ TIC.pdf

Checa, Antonio (1999). "La creatividad publicitaria en la era Internet". Questiones publicitarias, n. 8, pp. 95-108.

http://www.maecei.es/pdf/n8/articulos/la_creatividad_ publicitaria_en_la_era_de_internet.pdf

Corredor, Patricia (2010). "Bajo el signo de la integración: creatividad, innovación y tecnología al servicio de la publicidad en la era digital". Telos, n. 82, pp. 65-77.

http://sociedadinformacion.fundacion.telefonica.com/ seccion=1268\&idioma=es_ES\&id=2010020309240001\&activo=6. do

De-Salas-Nestares, María-Isabel (2010). "La publicidad en las redes sociales: de lo invasivo a lo consentido". Icono 14, v. 8, n. 1 , pp. 75-84.

http://www.icono14.net/ojs/index.php/icono14/article/ view/281

Del-Pino, Cristina (2007). "Nueva era en la comunicación comercial audiovisual: el marketing viral". Pensar la publicidad, v. 1, n. 2, pp. 63-76.

http://revistas.ucm.es/index.php/PEPU/article/view/ PEPU0707220063A

Del-Pino, Cristina (2011). "Redes sociales, comunicación publicitaria y usuario digital en la nueva era". Comunicación, v. 1, n. 9, pp. 163-174.

http://www.revistacomunicacion.org/pdf/n9/miscelanea/m01. Redes_sociales_comunicacion_publicitaria_y_usuario_digital_ en_la_nueva_era.pdf

Del-Pino, Cristina; Galán, Elena (2010). “Internet y los nue- 
vos consumidores". Telos, n. 82, pp. 55-64.

http://sociedadinformacion.fundacion.telefonica.com/ seccion=1268\&idioma=es_ES\&id=2010020215530001\&activo $=6$. do

Del-Río-Pérez, Jorge (2006). "La creatividad publicitaria en la literatura científica: una revisión". Comunicación y sociedad, v. XIX, n. 1, pp. 9-46.

http://www.unav.es/fcom/comunicacionysociedad/ descarga_doc.php?art_id=54

García-García, Alberto; Aguado-Guadalupe, Guadalupe (2011). "De un modelo de comunicación one-to-many a un modelo one-to-one en el entorno digital". Icono 14, v. 9, n. 1. pp.175-191.

http://www.icono14.net/ojs/index.php/icono14/article/ view $/ 225$

García-García, María; Castillo-Díaz, Ana; Carrillo-Durán, Victoria (2011). "Personalizar el mensaje online para construir una marca. Aproximación conceptual". Área abierta, n. 30, pp. 1-19.

http://revistas.ucm.es/index.php/ARAB/article/view/37839

Giménez-Cisneros, Susana; Perona-Páez, Juan-José (2011). "El impacto de los medios sociales en la relación entre usuarios y marcas: análisis y evaluación". Sphera pública, n. 11, pp. 237-260.

Gómez-Castallo, José-Domingo (2010). “La privacidad ante las nuevas técnicas publicitarias: la opuesta de la autorregulación". Telos, n. 82, pp. 11-17.

http://sociedadinformacion.fundacion.telefonica.com/ seccion=1268\&idioma=es_ES\&id=2010012908590001\&activo $=6$. do

Gómez-Tinoco, Alicia (2010). "El mobile marketing como estrategia de comunicación". Icono 14, v. 8, n. 1, pp. 238-260. http://www.icono14.net/ojs/index.php/icono14/article/ view/292

González-Díaz, Cristina; Francés-Barceló, María-Teresa (2011). “El videojuego como soporte publicitario: una aproximación al estudio del advergaming en las marcas de alimentación dirigidas al público infantil en España". Pensar la publicidad, v. 5, n. 1, pp. 223-247.

http://revistas.ucm.es/index.php/PEPU/article/view/36931

Grupo Spectus (2008). "Análisis creativo de la publicidad en los entornos virtuales". Comunicar, v. XVI, n. 31 , pp. 739742.

http://dx.doi.org/10.3916/c31-2008-03-075

Ha, Louisa (2008). "Online advertising research in advertising journal: A review". Journal of current issues and research in advertising, v. 30, n. 1, pp. 31-48.

http://dx.doi.org/10.1080/10641734.2008.10505236

Infoadex (2012). "Resumen. Estudio Infoadex de la inversión publicitaria en España 2012".

http://www.infoadex.es/Resumen_Estudio_Inversiones_InfoAdex_2012.pdf

Jones, Daniel E. (1998). "Investigación sobre comunicación en España: evolución y perspectivas". ZER. Revista de estudios de comunicación, v. 3, n. 5, pp. 13-51. http://www.ehu.es/zer/es/hemeroteca/articulo/investigacionsobre-comunicacion-en-espana-evolucion-y-perspectivas $/ 58$

Lamas, Eloy (2010). “¿ Y ahora qué?”. Telos, n. 82, pp. 6-7. http://sociedadinformacion.fundacion.telefonica.com/ seccion $=1268 \&$ idioma $=e s \_$ES\&id $=2010012912020001$ \&activo $=6$. do

López-de-Aguileta, Carmen; Torres, Emma (2007). “Medios y soportes alternativos para una publicidad convencional: publicidad "off the line". Pensar la publicidad, v. 1, n. 2, pp. 117-130.

http://revistas.ucm.es/index.php/PEPU/article/view/ PEPU0707220117A

Márquez, Israel (2011). "Música en la nube: experiencias musicales interactivas en la Red". Telos, n. 83, pp.139-148. http://sociedadinformacion.fundacion.telefonica.com/ seccion=1268\&idioma=es_ES\&id=2010051316230001\&activo $=6$. do

Martínez-García, María-Ángeles (2009). “Redes Sociales, Contenidos Publicitarios y Dispositivos Móviles. Análisis de una Relación de Conveniencia". Icono 14, v. 7, n. 1, pp. 162173.

http://www.icono14.net/ojs/index.php/icono14/article/ view/339

Martínez-Nicolás, Manuel (2009). “La investigación sobre comunicación en España. Evolución histórica y retos actuales". Revista latina de comunicación social, n. 64, pp. 1-14. http://www.ull.es/publicaciones/latina/09/art/01_800_01_ investigacion/Manuel_Martinez_Nicolas.html

Martínez-Pestaña, María-Jesús (2004). "La producción de tesis doctorales sobre temas publicitarios (1971-2001)". Documentación de las ciencias de la información, v. 27, pp. 237-267.

http://revistas.ucm.es/index.php/DCIN/article/view/ DCIN0404110237A/19300

Martínez-Rodrigo, Estrella; Sánchez-Martín, Lourdes (2012). "Publicidad en internet: nuevas vinculaciones en las redes sociales". Vivat academia, n. 117E, pp. 469-480.

http://www.ucm.es/info/vivataca/numeros/n117E/ DATOSS.htm

Matellanes, Mónica (2011). “Actitudes, comportamientos y usos de diferentes generaciones de usuarios en Internet", Vivat academia, n. 115, pp. 1-22.

http://www.ucm.es/info/vivataca/numeros/n115/DATOSS. htm

Melendo, Laura (2012). "Claves para valorar el marketing móvil". Vivat academia, n. 117E, pp. 51-62

http://www.ucm.es/info/vivataca/numeros/n117E/DATOSS.htm

Méndiz, Alfonso (2010). "Advergaming: concepto, tipología, estrategias y evolución histórica". Icono 14, v. 8, n. 1, pp. 37 $-58$.

http://www.icono14.net/ojs/index.php/icono14/article/ view $/ 279$

Moreno-Castro, Carolina (2003). "La investigación universitaria en periodismo científico". Ámbitos, n. 9-10, pp. 121- 
141.

http://grupo.us.es/grehcco/ambitos09-10/carolina.pdf

Niño-González, José-Ignacio; García-Guardia, María-Luisa (2012). "Marketing mobile. La importancia del modo de recepción de los mensajes publicitarios". Icono 14, v. 10, n. 1 , pp. 230-248.

http://www.icono14.net/ojs/index.php/icono14/article/ view/183

Orozco, Jaime Alberto; Roca, David (2011). "La incidencia de la RSC en la marca: del ensayismo español al cientificismo anglosajón". Questiones publicitarias, n. 16, pp. 91-107. http://www.maecei.es/pdf/n16/articulos/A6.La_incidencia_de_ la_RSC_en_la_marca_del_ensayismo_espanol_al_cientificismo_ anglosajon.pdf

Papí-Gálvez, Natalia; López-Berna, Sonia (2012). “Medios online y publicidad. Perfiles profesionales en la educación superior". Vivat academia, n. 117 E, pp. 672-700.

http://www.ucm.es/info/vivataca/numeros/n117E/ DATOSS.

Pérez-Bes, Francisco (2010). "La publicidad en las redes sociales". Telos, n. 85, pp. 58-68.

htt $p: / /$ sociedadinformacion.fundacion. telefonica.com/seccion=1268\&idioma=es_ ES\&id $=2010110408540001$ \&activo $=6$.do

Prado, Emili; Franquet, Rosa; Ribes, Francesc-Xavier; Soto, María-Teresa; Fernández-Quijada, David (2007). "La publicidad televisiva ante el reto de la interactividad". Questiones publicitarias, v.1, n. 12, pp. 13-28.

http://www.maecei.es/pdf/n12/articulos/La_publicidad_ televisiva_ante_el_reto_de_la_interactividad.pdf

PricewaterhouseCoopers; Interactive Advertising Bureau Spain. La inversión publicitaria en medios digitales en 2011. http://www.iabspain.net/wp-content/uploads/ downloads/2012/05/Estudio_inversion_publicidad_IAB_ Spain_2011.pdf

Rausell-Köster, Claudia (2004). "La publicidad en la web: hacia el patrocinio y el banner narrativo audiovisual". Questiones publicitarias, v. 1, n. 9, pp. 103-127.

http://www.maecei.es/pdf/n9/articulos/la_publicidad_ en_la_web_hacia_el_patrocinio_y_el_banner_narrativo_ audiovisual.pdf

Roca, David; Mensa, Marta (2009). “Las metodologías utilizadas en las investigaciones de creatividad publicitaria (1965-2007)". Comunicación y sociedad, v. XXII, n. 2, pp. 7-34.

http://hdl.handle.net/10171/8629

Romero, María; Fanjul, Carlos (2010). “La publicidad en la era digital: el microsite como factor estratégico de las campañas publicitarias on-line". Comunicar, v. XVII, n. 34, pp. 125-134.

http://dx.doi.org/10.3916/C34-2010-03-12
Sanz-Blas, Silvia; Martí-Parreño, José; Ruiz-Mafé, Carla (2012). "Aplicaciones publicitarias para móvil: conocimiento, actitudes, motivos de uso y valoración por parte de los adolescentes españoles". Pensar la publicidad, v. 6, n. 1, pp. 255-270.

http://revistas.ucm.es/index.php/PEPU/article/view/38665

Scolari, Carlos-Alberto; Navarro-Güere, Héctor; PardoKuklinski, Hugo; García-Medina, Irene (2009). “Marketing móvil en Cataluña: mapa de actores, contenidos y tendencias". Pensar la publicidad, v. 3, n. 1, pp. 147-162.

http://revistas.ucm.es/index.php/PEPU/article/view/ PEPU0909120147A

Selva, David (2012). "La difusión del videoclip a través de internet: nuevos fenómenos en el entorno on line". Telos, n. 90, pp. 43-53.

http://sociedadinformacion.fundacion.telefonica.com/ seccion=1268\&idioma=es_ES\&id=2012020211040001\&activo=6. do

Tapia-Frade, Alejandro; López-Iglesias, Matías; GonzálezPosada, Pablo (2009). "Publicidad in-game. Los videojuegos como soporte publicitario". Pensar la publicidad, v. 3, n. 2, pp. 73-88.

http://revistas.ucm.es/index.php/PEPU/article/view/ PEPU0909220073A

Torrado, Susana; San-Nicolás, César; Gómez-Baceiredo, Beatriz (2011). "Mentiras desbocadas, medios de comunicación, internet y marketing viral”. Vivat academia, n. 115, pp. 1-18.

http://www.ucm.es/info/vivataca/numeros/n115/DATOSS. htm

Torres, Emma; Corbacho, Juan-Manuel (2012). "Redes sociales y docencia en los estudios de publicidad". Vivat academia, n. 117E, pp. 795-807.

http://www.ucm.es/info/vivataca/numeros/n117E/ DATOSS.htm

Trapero-de-la-Vega, José-Ignacio (2011). “Propuestas publicitarias en internet de facultades de comunicación en España". Área abierta, n. 28, pp. 1-19.

http://revistas.ucm.es/index.php/ARAB/article/view/ ARAB1111130005A

Trapero de la Vega, José Ignacio (2012). “Creando historias interactivas para construir microsites 2.0: la actitud cautivadora de un nuevo código visual". Pensar la publicidad, v. 6, n. 1 , pp. 63-80.

http://revistas.ucm.es/index.php/PEPU/article/view/38656

Vázquez-Gestal, Montse; Pérez-Seoane, Jesús (2010). “EI uso de internet como medio publicitario en los mercados regionales. Percepción de los profesionales gallegos". Telos, n. 82, pp. 88-94.

http://sociedadinformacion.fundacion.telefonica.com/ seccion=1268\&idioma=es_ES\&id=2010020313200001\&activo=6. do 